\title{
Морфемный состав слова в русском и китайском языках: сопоставительный анализ
}

\author{
Багдуева А.В. \\ Байкальский государственный университет, \\ Россия, 664003, г. Иркутск, ул. Ленина, 11 \\ E-mail: bagduevanna@mail.ru
}

\begin{abstract}
Аннотация. Хотя морфемы всесторонне изучены и теоретически обоснованы, на сегодняшний момент отсутствует сопоставительный анализ морфемного строя данных языков. Наличие подобного анализа способно послужить лучшему пониманию структуры неродного языка, а значит, содействовать формированию лексической и грамматической компетенции. В связи с этим, автором рассматриваются и сопоставляются единицы русского и китайского слова. Путем теоретического анализа выявляются основные расхождения, сходства и взаимосвязи в классификации морфем. Автор также объясняет и обосновывает основные принципы морфемного разбора в данных языках. Результаты исследования могут представлять интерес для русистов и китаистов при создании упражнений для решения лингвистической задачи - членения слова на составляющие.
\end{abstract}

Ключевые слова: китайский язык, русский язык, морфема, морфемный разбор, морфемный анализ.

Для цитирования: Багдуева А.В. 2020. Морфемный состав слова в русском и китайском языках: сопоставительный анализ. Вопросы журналистики, педагогики, языкознания, 39 (2): 263-270. DOI $10.18413 / 2712-7451-2020-39-2-263-270$

\section{Morphemic composition of the word in russian and chinese languages: comparative analysis}

\author{
Anna V. Bagdueva \\ Baikal State University, \\ 11 Lenina St, Irkutsk, 664003, Russia \\ E-mail: bagduevanna@mail.ru
}

\begin{abstract}
A comparative analysis of Russian and Chinese languages at the morphemic level in modern linguistics is not sufficiently represented. Although morphemes are comprehensively studied and theoretically substantiated, there is no comparative analysis of the morpheme structure of these languages. The presence of such an analysis can lead to better understanding the structure of the foreign language, and therefore, contribute to the formation of lexical and grammatical competence. In this regard, the author considers and compares units of the Russian and Chinese word. Through theoretical analysis the main differences, similarities and relationships in the classification of morphemes are identified. The author also explains and justifies the basic principles of morphemic analysis in the languages. The article may be of interest to Russian and Chinese linguists in the sphere of second language acquisition. The article's material can be used to create exercises for solving the linguistic problem - dividing a word into components.
\end{abstract}

Keywords: Chinese, Russian, morpheme, morphemic parsing, morphemic analysis.

For citation: Bagdueva A.V. 2020. Morphemic composition of the word in russian and chinese languages: comparative analysis. Issues in Journalism, Education, Linguistics, 39 (2): 263-270 (in Russian). DOI 10.18413/2712-7451-2020-39-2-263-270 


\section{Введение}

Любой язык представляет собой взаимосвязанную и взаимопроникающую уровневую систему. Предложение членится на фразы, фразы - на слова, слова - на морфемы. Морфема выступает наименьшей звукосмысловой единицей языка, влияющей на расширение словарного запаса учащихся.

Российские лингвисты единодушны в том, что членение слова на составляющие развивает орфографическую зоркость, логическое мышление, повышает грамотность, способствует развитию речи [Постникова, Чудаева, 2017]. В свою очередь, исследователи из КНР согласны в том, что осмысление китайской морфемы улучшает понимание текста при чтении, влияет на формирование грамматической и синтаксической компетенции [Wu Sina, 2017; Yang Xuming, Zhao Ying, 2019].

Морфемный состав русского слова чрезвычайно разнообразен, в «Русской грамматике» выделяется более шестидесяти комбинаций морфем [Русская грамматика, 1980, c. 130]. Китайский же язык отличается скудностью морфологии. Гэ Бэньи говорит о десяти типах сочетаний морфем [Ge Benyi, 2017, с. 31]. Это не значит, что структура китайского слова проще или беднее. Скорее можно говорить о высокой концентрации грамматики в русском слове и низкой - в предложении, а в китайском языке наоборот: грамматические показатели распространены в предложении, но почти отсутствуют в лексической единице.

В российских научных кругах принято рассматривать китайское слово с позиции его структуры: взаимосвязи морфем, выражающихся в семантических отношениях и последовательности компонентов. В свою очередь, русское слово в Китае в основном изучается с точки зрения словообразования и словоизменения. Как следствие, теоретическая база по морфемному составу слова в рамках русско-китайского интерязыка является недостаточно разработанной. Разбор слова по составу должен предшествовать морфологическому и синтаксическому анализу. Игнорирование освоения единиц слова при обучении схоже со строительством здания без фундамента [Добренко, Соколова, 2018].

В данной статье мы, абстрагируясь от семантических и грамматических внутрисловных связей между морфемами, затрагиваем только формальную сторону слова состав, тем самым отделяя морфемный анализ от словообразовательного. Морфемный анализ устанавливает из каких частей состоит слово, а словообразовательный - раскрывает конкретный способ образования слова [Шакун, 1975, с. 149]

Целью исследования является выявление сходств в морфемном строении слова русского и китайского языков. Объектом исследования выступают морфемы этих двух языков. Предметом - морфемы, вычленяемые при разборе слова. Гипотезой исследования является предположение о том, что, несмотря на очевидную разницу в составе слова в китайском и русском языках, существуют сходные закономерности его строения.

Методологической основой выступают принципы морфемики и морфологии, изложенные в «Русской грамматике» [1980], в трудах признанных ученых, таких как В.М. Солнцев [1995], А.Л. Семенас [2005], И.Д. Кленин и В.Ф. Щичко [2013], Jerome L. Packard [2018] и GeBenyi [2018]. Научные публикации таких авторов, как DengShangqing [2018], YangXuming и ZhaoYing [2019], затрагивающие актуальные вопросы морфологии современного китайского языка - классификацию, грамматикализацию и деморфемизацию морфем, - были подвергнуты критическому анализу и также вошли в методологическую базу данного исследования.

\section{Единицы русского слова}

Элементы, входящие в состав русского слова, отличаются от элементов китайского слова. Прежде всего отметим, что слово в русском языке - это единица, обладающая 
звуковой оболочкой, лексическим значением, единым ударением, грамматическими формами [Нетяго, Дюзенли, 2016, с. 6] и графически выражается буквами. При морфемном анализе слово рассматривается как структурно-семантическое единство значимых частей [Козлова, 2013].

Русское слово состоит из морфем: корней и аффиксов. Корень заключает в себе основной элемент лексического значения. Аффиксы служат для образования нового слова или его форм. Словообразовательные аффиксы в совокупности с корнем формируют семантику слова и выступают его основой. Слова делятся на простые и сложные, первые состоят из одной основы, вторые - из двух и более.

Аффиксы делятся на префиксы (приставки), суффиксы, интерфиксы, nостфиксы и флексии (окончания). Приставка располагается перед корнем, суффикс - после корня, окончание - в конце слова, постфикс - после окончания, интерфикс - между основами сложного слова.

Приставки служат в словообразовательных целях: ходить - в-ходить. Суффиксы и постфиксы в русском языке в основном образуют новые слова: лед - лед-ник, отправил отправил-ся, реже - новые формы: тонк-ий - тонь-ие, иди - иди-те. Интерфиксы указывают на связь простых основ: caм-о-лет. Окончания приводят только к изменению морфологических значений: стен-a, стен-bí, сте́н-bl.

Согласно «Русской грамматике» слово существует как система словоформ, а морфема - как совокупность морфов [Русская грамматика, 1980, с. 123]. Морфема - это родовое понятие, а морф - видовое [Ишкильдина, 2017]. Так, слово дом включает в себя двенадцать словоформ: дом, до́ма, дому, дом, домом, (о) доме, дома́, домов, домам, дома́, домами, (о) домах. Морфы друг- и друж- в словах друг и дружок представляют одну корневую морфему.

Таким образом, в морфемном разборе используется словоформа как конкретная реализация слова в высказывании, ее единицами выступают приставка, корень, суффикс, инфикс, постфикс и окончание.

\section{Морфемный состав русского слова}

Основываясь на принципах морфемики, изложенных в «Русской грамматике», выделим 4 основных типа морфного строения простого слова (с одним корнем) исходя из того, входят или не входят окончания и постфиксы в состав слова [Русская грамматика, 1980, с. 130]. Рассмотрим их.

Словоформы без окончания и постфикса. Это лексемы, выраженные конструкцией «приставка (приставки) + корень + суффикс (суффиксы)». Словоформы данного типа могут состоять только из одного корня, как слово круг, или «прицеплять» приставки и суффиксы, как в словах от-ныне и по-утр-у .

Словоформы с окончанием и без постфикса. Это лексические единицы, выраженные конструкцией «приставка (приставки) + корень + суффикс (суффиксы) + окончание»: нес-y, от-вез-ут, сер-еньк-ий, раз-брак-ов-к-а. Окончание добавляют изменение по роду, числу, падежу и лицу.

Словоформы с постфиксом. Это лексемы, имеющие конструкцию «приставка (приставки) + корень + суффикс (суффиксы) + постфикс»: где-то, от-куда-то, тряс-я-сь, испек-ии-сь.

Словоформы с окончанием и постфиксом. Это лексемы, выраженные конструкцией «приставка (приставки) + корень + суффикс (суффиксы) + окончание + постфикс»: берут-ся, за-тряс-ут-ся, горд-и-ви-ий-ся, по-из-гряз-н-и-л-и-сь. 
Словоформы со сложной основой, т.е. обязательно включающие два и более корня, делятся на два типа: 1) содержащие интерфикс: сам-о-лет, оч-е-видец, 2) не содержащие интерфикс: сверх-сложный, худ-совет.

\section{Единицы китайского слова}

Китайское слово обладает фонетической формой, определенным значением, закрепленной конструкцией и выступает строительным блоком для создания предложений [Гэ Бэньи, 2017, с. 28]. В китайском языке делимость слова доходит только до слога [Задоенко, Хуан Шуин, 1993, с. 8]. Теперь вооружимся понятиями о единицах слова.

Китайские слова состоят из морфем, формально выраженных иероглифами, и делятся на простые и сложные. Простые (односложные) слова состоят из одной морфемы и составляют исходный лексический инвентарь языка [Семенас, 2005, с. 27]. Сложные слова есть конструкция из нескольких морфем.

Морфема - это базовая грамматическая единица, обладающая единством звучания и значения, являющаяся предпосылкой и основой существования других грамматических единиц [YangXuming, ZhaoYing, 2019]. Морфемы делятся на свободные и связанные; первые - это по сути простые слова, способные выступать словообразовательными компонентами, а последние представляют собой корни и аффиксы [Солнцев, 1995, с. 61].

Связанная корневая морфема обладает лексическим значением, но не употребляется вне слова, а значит, не может являться синтаксическим отрезком предложения. Между свободными и связанными морфемами существует ряд единиц, обладающих разной степени свободы [Yang Xuming, Zhao Ying, 2019; Packard, 2015; Солнцев, 1995]. Полусвободные морфемы способны выступать словами лишь в узком круге сочетаний [Packard, 2015, с. 264], в остальных случаях они выполняют функции корневой морфемы.

Говоря об аффиксах лучше употреблять термин полуаффиксы, поскольку подобные грамматические единицы обладают разной интенсивностью проявления лексического значения и синтаксической самостоятельности [Солнцев, 1995; Кленин, Щичко, 2013]. Ониуказывают на отнесенность слова к определенному смысловому разряду и определенной части речи [Горелов, 1982]. Так, полусуффикс 匠 демонстрирует принадлежность к ремесленному делу: 木匠 - столяр, 铁匠 - кузнеи, 瓦匠 - каменщик и т.д. Слово 到, в свою очередь, способно выступать и полусуффиксом, и синтаксической единицей, сравним: 买到 купить и 我到了 - Я прибыл.

Морфема обладает и планом выражения, и планом содержания, т.е. это двусторонняя единица, формальная сторона которой неотделима от семантической [Хаматова, 2003]. При потере лексического значения происходит деморфемизация (非语素化), и тогда остается только формальная сторона - начертание и фонетическая оболочка [Deng Shangqing, 2018]. Подобные морфемы мы назовем формальными. Они могут быть исконно китайскими (吩, 蜘, 咐), либо представлять фонетическую кальку иностранных слогов, например, как в слове 咖啡 - kāfēi, кофе.

Таким образом, в китайском языке простоеслово и сложноеслово являются единицами предложения. Свободная корневая морфема, связанная корневая морфема, полусвободная корневая морфема, формальная морфема и полуаффикс (аффикс) выступают составными единицами китайского слова.

\section{Морфемный состав китайского слова}

Рассмотрим типы морфемного строения слова. Гэ Бэньи выделяет всего восемь типов [Ge Benyi, 2017].

Простое (односложное) слово. Это самостоятельные единицы, состоящие из одной свободной корневой морфемы: 山 - гора, 飞-летать, 红 - красный, 而 - но и т.п. 
Контекстуально обусловленное простое слово. Это самостоятельные единицы, состоящие из одной полусвободной корневой морфемы: 民 - народ, 子 - дети, 发 - волосы и другие. Так, глагол 拍摄 - фотографировать является широко употребляемым, а его компонент 摄 проявляется как слово лишь в определенном смысловом окружении, например, как во фразе 本报记者摄 - снято штатным корреспондентом.

Сложное слово, состоящее из формальных морфем. В подобных конструкциях составляющие могут быть связанными или свободными, обладать значением или быть семантически пустыми. К примеру, слова 志态 - неспокойный и 玻璃 - стекло морфологически неразложимы, каждый компонент по отдельности не обладает каким-либо смыслом. А в таких словах, как 沙发 - диван и 加拿大 - Канада, представляющих собой фонетическую кальку английских единиц sofa и Canada, значение морфем не учитывается.

Сложное слово, включающее в себя свободные корневые морфемы и формальную морфему. Структура подобных конструкций включает фонетическое заимствование и значащую морфему: 卡车 - грузовик, 酒吧 - бар, 法兰线 - фланель и т.п. Например, в слове 啤酒 - пиво, элемент 酒 - алкоголь выступает смыслообразующим компонентом, а морфема 啤 - pí, являясь звуковой калькой от английского beer (пиво), уточняет вид алкогольного напитка.

Сложное слово, включающее в себя свободные корневыеморфемы и полуаффикс. Китайский язык обладает скудной морфологией, поэтому некоторые простые слова, входя в состав сложного слова, обладают способностью «обесцвечивать» свою семантику, трансформируясь в грамматические морфемы. Такие элементы называются грамматикализованными: 阿, 化, 溜溜 и др. Так, компонент 子- zі в слове 帘子 - шторы выполняет функцию суффикса существительного, а в слове 鱼子 - икра он является лексически значимой корневой морфемой (рыба - 鱼 плюс дети - 子).

Сложное слово, включающее свободную и связанную корневые морфемы. В основном это двусложные слова типа 宁静 - тихий (мирный + спокойный) и 逃遁 - cnaсаться бегством (скрываться + бежать). Компоненты 宁 и 遁 являются свободными, а 静 и 逃 - связанными.

Сложное слово, состоящее из связанных корневых морфем. Морфемы подобных конструкций лишь формируют новое значение и неспособны выступать отдельными словами: 监督 - контролировать (наблюдать + надзирать), 业务 - бизнес (деятельность + дела).

Сложное слово, состоящее из свободных корневых морфем. Морфемы подобной конструкции способны выступать простыми словами вне данного слова. Так, компоненты слов 地球 - Земля (земля + шар), 笨重 - тяжелый (громоздкий, серьезный), 带头 возглавлять (вести + голова) по отдельности сами являются лексическими единицами. Необходимо понимать, что подобные слова не являются словосочетаниями. Например, слово 白菜 (белый + овощ) - китайская капуста является единым целым и его значение нельзя расширить до значения словосочетания 白的菜 - бельй овощ.

Редуплицированное слово, сохранившее значение его морфемы. Редупликация это удвоение слога или корня [Дюзенли, Сунь Эрюй, 2015]. Несвободная морфема, даже обладая семантикой, способна использоваться только в словообразовательных целях. Посредством редупликации подобные единицы становятся словами, при этом значение компонента распространяется на новое слово: 伯 - дядя $\rightarrow$ 伯伯 - дядя, 快 - недовольный $\rightarrow$ 快快 - недовольный, 纷 - во множестве $\rightarrow$ 纷纷- во множестве и т.д. Следует отметить, что некоторые редупликанты являются полусамостоятельными и в определенном грамматическом окружении способны выступать словами: 姑- тетя и 姑姑 - memя, 星 - звезда и 
星星 - звезд $a$, 棒 - палка и 棒棒- палка. Например, в выражении 妈妈, 我回来啦 - «Мамa, я пришел» можно употребить и 妈 - мама, и 妈妈 - мама.

Редуплицированное слово с новым значением. При редупликации получаемое слово может приобрести новое значение, отличное от значения его компонента. Например: 斤- полкилограмма $\rightarrow$ 斤斤 - суетится, 统 - объединять $\rightarrow$ 统统 - всё, 断- разрубать $\rightarrow$ 断断 - решительно и другие. Редупликанты могут быть как свободными (斤, 区, 通), так и связанными (翼, 奕, 济).

\section{Выводы}

При членении китайского слова выделяются следующие части: свободная корневая морфема, полусвободная корневая, связанная корневая, формальная морфема и полуаффикс. При членении русского слова выделяются следующие единицы: приставка, корень, суффикс, инфикс, постфикс и окончание.

В ходе анализа морфемного строения слова в русском и китайском языках были выявлены следующие различия:

1) в китайском языке для разбора используется слово, в русском - словоформа;

2) в китайском языке сложное слово не обязательно содержит несколько корневых морфем, в русском - обязательно;

3) в китайском языке любое слово и есть основа, в русском языке основа слова вычленяется путем отброса формообразующих аффиксов (окончаний и некоторых суффиксов);

4) в китайском слове легко вычленяются морфемы, в русском - нет;

5) в китайском языке деривацию имеет корневая морфема (свободная, полусвободная, связанная), а в русском - аффиксальная (приставка, суффикс, префикс и т.д.);

6) в китайском слове не вычленяются окончания, инфиксы и постфиксы, в русском - формальные морфемы и полуаффиксы.

Безусловно, все полуаффиксы китайского языка можно разделить на префиксы и суффиксы как в русском языке. Разделение полуаффиксов на словообразовательные (复, 无, 化 и др.) и формообразующие (们, 着, 了 и др.) морфологически значимо, но не является важным для морфемного разбора китайского слова.

Не вызывает сомнений, что корневые морфемы в русском языке можно подразделить на свободные и связанные. Так, единица стол является свободной, посколькуспособна выступать и словом, и корневой морфемой (стол-стол-ом), а корень -друж- (друж-ба, друж-еский) не употребляется отдельно и есть только морфема. Более того, среди русских морфем можно вычленить и полуаффиксы. Например, приставку еже- в слове ежегодный можно отнести к полуаффиксам, поскольку она обладает явным значением - каждый [DingYu, 2015].

Таким образом, трудные для понимания единицы китайского и русского слова взаимно объяснимы путем их теоретического осмысления. Исходя из этого, были выявлены следующие сходства:

1) в обоих языках корневая морфема является основным значащим элементом слова;

2) в обоих языках существуют слова, содержащие две и более корневые морфемы;

3) в обоих языках существуют свободные и связанные корневые морфемы;

4) в обоих языках присутствуют аффиксы (полуаффиксы), обладающие лексическим значением разной интенсивности;

5) в обоих языках существуют словообразовательные и словоизменительные аффиксы (полуаффиксы);

6) в обоих языках позиция префикса и суффикса одинакова.

В целом гипотеза исследования о существовании сходных закономерностей строения слова в русском и китайском языках подтверждена. Понимание единиц слова таких 
разных языков приходит путем их сравнения на теоретическом уровне. Вооружившись выявленными сходствами и различиями, изучающие иностранный язык смогут более осмысленно решать практические задачи - морфемный и морфологический разбор иностранного слова.

Результаты исследования могут быть использованы для составления упражнений по морфемному разбору при изучении русского или китайского языка как иностранного, поскольку понимание частей слова лежит в основе формирования морфологической, а значит, и грамматической компетенции обучающегося.

\section{Список источников}

Нетяго Н.В., Дюзенли М.В. 2016. Лексикология современного русского языка: Краткий курс для иностранных учащихся. Екатеринбург, Изд-во Урал. ун-та, 100 с.

\section{Список литературы}

1. Горелов В.И. 1982. Грамматика китайского языка. М., Просвещение, 280 с.

2. Добренко Е.И., Соколова Е.В. 2018. К вопросу о методических основах преподавания русского языка как родного, неродного и иностранного. Лингвокультурология, 12: 78- 84.

3. Дюзенли М.В., Эрюй С. 2016. Явление редупликации в русском и китайском языках: к постановке проблемы. В кн.: Русский язык и лингвокультура в сопоставительном аспекте. Материалы ежегодной международной конференции кафедры русского языка для иностранных учащихся, Екатеринбург, 01-02 июня 2015 г. Под ред. У.С. Кутяевой. Екатеринбург, УрФУ им. первого Президента России Б. Н. Ельцина: 43-51.

4. Задоенко Т.П., Шуин Х. 1993. Основы китайского языка. Вводный курс. 2-е изд., испр. М., Наука, Восточная литература РАН, 271 с.

5. Ишкильдина 3.К. 2017. Лингвистическая природа морфа и морфемы в русском и башкирском языках. Доклады Башкирского университета, 2 (1): 120- 123.

6. Кленин И.Д., Щичко В. Ф. 2013. Лексикология китайского языка. М., Восточная книга, $272 \mathrm{c}$.

7. Козлова М.М. 2013. Морфемный разбор слова как средство формирования языковой и коммуникативной компетенции учащихся 4-5-х классов. Филологическиенауки. Вопросытеорииипрактики, 1 (19): 104-108.

8. Постникова О.А. 2017. О некоторых трудностях, возникающих при изучении состава слова на занятиях по русскому языку как иностранному. Актуальные проблемы гуманитарных и социально-экономических наук, 11 (52): 62-64.

9. Русская грамматика. 1980. Под ред. Н. Ю. Шведовой. Т. 1. М., Наука, 789 с.

10. Семенас А.Л. 2005. Лексика китайского языка. М., Восток-Запад, 310 с.

11. Солнцев В.М. 1995. Введение в теорию изолирующих языков. М., Восточная литература PAH, $352 \mathrm{c}$.

12. Хаматова А.А. 2003. Словообразование современного китайского языка. М., Муравей, $222 \mathrm{c}$.

13. Шакун Л.М. 1975. Методы построения морфемного словаря. В кн.: Методы изучения лексики. Подред. А. Е. Супруна. Мн., Изд-воБГУ: 147-152.

14. Deng Shangqing. 2018. About the Non-Morphemeization of Modern Chinese Morpheme. Literature Education, 2 (6): 12-14 (in Chinese)

15. Ding Yu. 2015. Shallow Quasi-Affixes in Russian. Learning Russian, 6: 56-60 (in Chinese)

16. Ge Benyi. 2017. Modern Chinese Lexicology. London and New York, Routledge, 231 p.

17. Packard J.L. 2015. Morphology: Morphems in Chinese. The Oxford Handbook of Chinese Linguistics. Ed. William S-Y. Wang, Chaofen Sun. OxfordUniversityPress:263-273.

18. Yang Xuming, Zhao Ying. 2019. Review of Studies on the Determination, Classification Morpheme as Grammar Unit. Journal of Anyang College of Education, 3: 113-117 (in Chinese)

19. Wu Sina. 2017. The Role of Morphological Awareness in Reading Comprehension of TCSL. Chinese Teaching and Research, 1: 34-41 (in Chinese) 


\section{References}

1. Gorelov V.I. 1982. Grammatika kitayskogo yazyka [Chinese grammar]. M., Publ. Prosveshchenie, $280 \mathrm{p}$.

2. Dobrenko E.I., Sokolova E.V. 2018. To the question of the methodological foundations of teaching the Russian language as a native, step-native and foreign. Linguoculturology, 12: 78-84 (in Russian)

3. Dyuzenli M.V., Sun' Eryuy. 2016. Yavlenie reduplikatsii v russkom i kitayskom yazykakh: k postanovke problem [The phenomenon of reduplication in Russian and Chinese: to the statement of the problem]. In: Russkiy yazyk i lingvokul'tura v sopostavitel'nom aspekte [Russian language and linguistic culture in a comparative aspect]. Materialy ezhegodnoy mezhdunarodnoy konferentsii kafedry russkogo yazyka dlya inostrannykh uchashchikhsya, Ekaterinburg, 01-02 iyunya 2015 g. Ed. U.S. Kutyaevoy. Ekaterinburg, UrFU im. pervogo Prezidenta Rossii B.N. El'tsina: 43-51.

4. Zadoenko T.P., Shuin Kh. 1993. Osnovy kitayskogo yazyka Vvodnyy kurs. [The basics of the Chinese language. Introductory course]. 2-e izd., ispr. M., Publ. Nauka, Vostochnaya literature RAN, 271 p.

5. Ishkil'dina Z.K. 2017.The linguistic nature of the morph and morpheme in Russian and Bashkir languages. Reports of Bashkir University, 2 (1): 120-123 (in Russian)

6. Klenin I.D., Shhichko V.F. 2013. Leksikologija kitajskogo jazyka [Lexicology of the Chinese Language]. M., Publ. Vostochnaja kniga, 272 p.

7. Kozlova M.M. 2013. Morphemic analysis of word as means of language and communicative competences formation of the $4-5^{\text {th }}$ forms schoolchildren. Philological sciences. Questions of theory and practice, 1 (19): 104-108 (in Russian)

8. Postnikova O.A. 2017. About some difficulties arising from studying the composition of words in russian languages as a foreign language. Actual problems of the humanities and socio-economic sciences, 11 (52): 62-64 (in Russian) ka, $789 \mathrm{p}$.

9. Russkaya grammatika [Russian gramma]. 1980. Ed. N.Yu. Shvedovoy. Vol. 1. M., Publ. Nau-

10. Semenas A.L. 2005. Leksika kitayskogo yazyka [Chinese vocabulary]. M., Publ. VostokZapad, $310 \mathrm{p}$.

11. Solntsev V.M. 1995. Vvedenie v teoriyu izoliruyushchikh yazykov [Introduction to the theory of isolating languages]. M., Publ. Vostochnaya literatura RAN, 352 p.

12. Hamatova A.A. 2003. Slovoobrazovanie sovremennogo kitajskogo jazyka [Word-formation of the Modern Chinese Language]. M., Publ. Muravej, $222 \mathrm{p}$.

13. Shakun L.M. 1975. Metody postroeniya morfemnogo slovarya [Methods for constructing a morpheme dictionary]. In.: Metody izucheniya leksiki [Vocabulary Learning Methods]. Pod red. A.E. Supruna. Mn., Publ BGU: 147-152.

14. Deng Shangqing. 2018. About the Non-Morphemeization of Modern Chinese Morpheme. Literature Education, 2 (6):12-14 (in Chinese)

15. Ding Yu. 2015. Shallow Quasi-Affixes in Russian. Learning Russian, 6: 56-60 (in Chinese)

16. Ge Benyi. 2017. Modern Chinese Lexicology. London and New York, Routledge, 231 p.

17. Packard J. L. 2015. Morphology: Morphems in Chinese. The Oxford Handbook of Chinese Linguistics. Ed. William S-Y. Wang, Chaofen Sun. OxfordUniversityPress: 263-273.

18. Yang Xuming, Zhao Ying. 2019. Review of Studies on the Determination, Classification Morpheme as Grammar Unit. Journal of Anyang College of Education, 3: 113-117 (in Chinese)

19. Wu Sina. 2017. The Role of Morphological Awareness in Reading Comprehension of TCSL. Chinese Teaching and Research, 1: 34-41 (in Chinese)

\section{ИНФОРМАЦИЯ ОБ АВТОРЕ}

Багдуева Анна Вячеславовна, аспирант кафедры иностранных языков Байкальского государственного университета, г. Иркутск, Россия

\section{INFORMATION ABOUT THE AUTHOR}

Anna V. Bagdueva, postgraduate student of the Department of foreign languages,, Baikal State University, Irkutsk, Russia 